\title{
HYPERTENSION AS A PREDICTOR IN-HOSPITAL MORTALITY AMONG PATIENTS HAVING CONGESTIVE HEART FAILURE.
}

\author{
DR. MOIZ HASSAN AZDEE, MBBS, \\ DEPARTMENT OF MEDICINE, \\ NISHTAR HOSPITAL, MULTAN, PAKISTAN. \\ DR. KHAWAJA MUHAMMAD AFNAN, MBBS, \\ DEPARTMENT OF MEDICINE,
} NISHTAR HOSPITAL, MULTAN, PAKISTAN. DR. MUHAMMAD BASSIM ARSHAD, MBBS, DEPARTMENT OF MEDICINE, NISHTAR HOSPITAL, MULTAN, PAKISTAN.

\begin{abstract}
;
Background; Hypertension remains an important risk factor which contributes towards the worsening of the outcomes, consisting of cardio-renal anemia syndrome and its impact in heart failure remains to be complex and multifactorial. The current study was done to evaluate the role of hypertension on mortality among patients having congestive heart failure. Material and methods; This study included a total of 115 patients with congestive heart failure presenting at Nishtar Hospital Multan. These patients were followed till discharge to document in-hospital mortality during current hospitalization. All the sociodemographic distribution and other relevant information such as age, gender, area of residence, diabetes, hypertension, obesity, smoking, hyperlipidemia and mortality were noted in the proforma and data was entered and analyzed by SPSS version 22 for descriptive statistics and tests of significance. hypertension was cross-tabulated against in-hospital mortality using two by two table and chi-square test was applied at level of significance of 0.05 . Results; Among our 115 patients with congestive heart failure, $75(65.2 \%)$ were males and $40(34.8 \%)$ were females. Mean age of our patients with CHF was $57.17 \pm 11.65$ years ranging from 34 to 80 years. Although males were younger than female patients with congestive heart failure but this difference was not statistically significant $(\mathrm{p}=0.140)$. Seventy five $(65.2 \%)$ were from rural areas, $40(34.8 \%)$ were poor, $70(60.9 \%)$ from middle income families and only $5(4.3 \%)$ belonged to rich families. Mean body mass index (BMI) of patients with congestive heart failure was $26.12 \pm 2.93 \mathrm{~kg} / \mathrm{m}^{2}$ and $35(30.4 \%)$ were obese. Twenty five $(21.7 \%)$ were smokers. Forty five $(39.1 \%)$ had diabetes and $55(47.8 \%)$ had hypertension. In-hospital mortality in patients with congestive heart failure was 12 (10.4\%) and of these 12 mortalities, hypertension was noted in 11 (92\%) patients. Conclusion; Our study results have documented high frequency of hypertension among patients with congestive heart failure and hypertension was significantly associated with in - hospital mortality.
\end{abstract}

Keywords; Congestive Heart Failure, hypertension, in-hospital mortality.

DOI: $10.7176 / \mathrm{JMPB} / 55-07$

Publication date: May 31st 2019 


\section{Introduction;}

Cardiovascular diseases are the leading cause of mortality all over the world ${ }^{1-3}$, particularly in developing countries as the mortality rates among developed nations have dropped down significantly due to the availability of the healthcare facilities and advancements in techniques owing to patient care ${ }^{4-5}$. Heart failure is associated with significant medical, financial, psychological and societal burden with high rates of emergency department admissions $^{6}$. In USA, due to the heart failure (as a primary or secondary diagnosis), approximately more than 2.6 million patients get hospitalized every year and increase cost of healthcare budget enormously ${ }^{7}$. Congestive heart failure is a common health issue with high rates of mortality, emergency department/hospital admissions, reduced physical activity, poor productivity, loss of work and poor quality of life of the patients ${ }^{8-10}$. There are other modifiable as well as non-modifiable factors which lead to the worsening of the conditions of the patient and poor prognosis in addition to direct impact of congestive heart failure ${ }^{11-13}$. Anemia is also a major cause of disease morbidity, poor quality of life and productivity, reduced physical activity and is common entity among heart failure patients, hence representing a modifiable risk factor for poor prognosis and adverse clinical outcomes. It is also a strong predictor for the burden of related co-morbidities and for increased severity of the disease.

Hypertension remains an important risk factor which contributes towards the worsening of the outcomes, consisting of cardio-renal anemia syndrome and its impact in heart failure remains to be complex and multifactorial ${ }^{13-15}$.

Owing to role of hypertension in congestive heart failure in worsening of the condition and poor prognosis of the patients, this study was conducted to evaluate role of hypertension in CHF in Southern Punjab. This study was done to determine the role of hypertension associated with mortality to generate evidence on this topic as there is limited data on this topic from Pakistan.

\section{Material and methods;}

This study included a total of 115 patients with congestive heart failure presenting at Nishtar Hospital, Multan. Congestive Heart failure patients more than 20 years of age were included and CHF was defined as "patients having shortness of breath having Killip class I-IV (class I=no cracles, class II=JVP, class III=pulmonary edema, class IV=cardiogenic shock) and swelling of legs (assessed on clinical judgment by 2-3 minutes pressing of medial malleolus, if pit develops it was taken as positive) for more than 1 month (presence of all) which is consistent with echocardiographic findings (percentage of blood ejected with each beat - less than $50-75 \%$ " while patients having any malignancy, chronic obstructive pulmonary disease, poor intake and CABG were excluded. These patients were followed till discharge to document in-hospital mortality during current hospitalization. All the sociodemographic distribution and other relevant information such as age, gender, area of residence, diabetes, hypertension, obesity, smoking, hyperlipidemia and mortality were noted in the proforma and data was entered and analyzed by SPSS version 22 for descriptive statistics and tests of significance. Anemia was cross-tabulated against in-hospital mortality using two by two table and chi-square test was applied at level of significance of 0.05 .

\section{Results;}

Among our 115 patients with congestive heart failure, $75(65.2 \%)$ were males and $40(34.8 \%)$ were females. Mean age of our patients with $\mathrm{CHF}$ was $57.17 \pm 11.65$ years ranging from 34 to 80 years. Although males were younger than female patients with congestive heart failure but this difference was not statistically significant $(\mathrm{p}=0.140)$. Seventy five $(65.2 \%)$ were from rural areas, $40(34.8 \%)$ were poor, $70(60.9 \%)$ from middle income families and only $5(4.3 \%)$ belonged to rich families. Mean body mass index (BMI) of patients with congestive heart failure was $26.12 \pm 2.93 \mathrm{~kg} / \mathrm{m}^{2}$ and $35(30.4 \%)$ were obese. Twenty five $(21.7 \%)$ were smokers. Mean hemoglobin level of these patients was $11.36 \pm 2.55 \mathrm{~d} / \mathrm{dl}$ ranging from 6.6 to $14.7 \mathrm{~g} / \mathrm{dl}$ and anemia was documented in $60(52.2 \%)$ our patients. Forty five $(39.1 \%)$ had diabetes and $55(47.8 \%)$ had hypertension. In-hospital mortality in patients with congestive heart failure was $12(10.4 \%)$ and of these 12 mortalities, hypertension was noted in $11(92 \% \%)$ patients $(\mathrm{p}=0.005)$. 


\section{Discussion;}

Hypertension remains an important risk factor which contributes towards the worsening of the outcomes, consisting of cardio-renal anemia syndrome and its impact in heart failure remains to be complex and multifactorial ${ }^{16-17}$. Among our 115 patients with congestive heart failure, 75 (65.2\%) were males and 40 (34.8\%) were females. Silverberg et al ${ }^{18}$ documented $79 \%$ male patients having congestive heart failure, in compliance with our study results. Dai et al ${ }^{19}$ has also reported similar results. Rasheed et al ${ }^{20}$ reported $88 \%$ male patients with congestive heart failure showing compliance with our findings. Khan et al ${ }^{21}$ reported $60 \%$ male gender predominance in patients with CHF which are close to our study results. Nasir et al ${ }^{22}$ reported male gender preponderance with $65 \%$ which is close to our study results.

Mean age of our patients with CHF was $57.17 \pm 11.65$ years ranging from 34 to 80 years. Although males were younger than female patients with congestive heart failure but this difference was not statistically significant $(p=0.140)$. Rasheed et al $^{20}$ reported $50.77 \pm 7.53$ years mean age which is close to our study results. Nasir et al ${ }^{22}$ reported $60 \pm 13$ years mean age which is similar to that of our study results. Vim et al ${ }^{23}$ from Iran also reported 61 years mean age of the patients with congestive heart failure (CHF) which is close to our study results.

Mean body mass index (BMI) of patients with congestive heart failure was $26.12 \pm 2.93 \mathrm{~kg} / \mathrm{m}^{2}$ and 35 $(30.4 \%)$ were obese. Twenty five $(21.7 \%)$ were smokers. Forty five $(39.1 \%)$ had diabetes and $55(47.8 \%)$ had hypertension and hypertension was significantly associated with in - hospital mortality $(\mathrm{p}=0.005)$. Silverberg et al ${ }^{18}$ reported diabetes in $30 \%$, hypertension in $64 \%$ and smoking in $40 \%$ patients. These findings are close to our study results. Dai et al ${ }^{19}$ reported similar results.

\section{Conclusion;}

Our study results have documented high frequency of hypertension among patients with congestive heart failure. In-hospital mortality was significantly associated with hypertension.

\section{References;}

1. Finegold JA, Asaria P, Francis DP. Mortality from ischaemic heart disease by country, region, and age: Statistics from World Health Organisation and United Nations. Int J Cardiol. 2013;168(2):934-45.

2. Nowbar AN, Howard JP, Finegold JA, Asaria P, Francis DP. 2014 global geographic analysis of mortality from ischaemic heart disease by country, age and income: statistics from World Health Organisation and United Nations. Int J Cardiol. 2014;174(2):293-8.

3. Moran AE, Forouzanfar MH, Roth GA, Mensah GA, Ezzati M, Murray CJ, et al. Temporal trends in ischemic heart disease mortality in 21 world regions, 1980 to 2010: the Global Burden of Disease 2010 study. Circulation. 2014;129(14):1483-92.

4. Zhu KF, Wang YM, Zhu JZ, Zhou QY, Wang NF. National prevalence of coronary heart disease and its relationship with human development index: A systematic review. Eur J Prev Cardiol. 2016 Mar;23(5):530-43.

5. Fowkes FG, Rudan D, Rudan I, Aboyans V, Denenberg JO, McDermott MM, et al. Comparison of global estimates of prevalence and risk factors for peripheral artery disease in 2000 and 2010: a systematic review and analysis. Lancet. 2013 Oct 19;382(9901):1329-40.

6. Prado-Galbarro FJ, Del-Cura-González I, Garrido-Elustondo S, Gamiño-Arroyo AE, Sánchez-Piedra C, Sarriá Santamera A. A Comparison of Methods for Modeling Factors Associated with Hospital Admissions in Incident Cases of Heart Failure. Rev Esp Salud Publica. 2017 May 24;91. pii: e201705034.

7. Alexandrakis MG, Tsirakis G. Anemia in Heart Failure Patients. ISRN Hematol. 2012;ID 246915. http://dx.doi.org/10.5402/2012/246915

8. Badreddin A, Fady Y, Attia H, Hafez M, Khairallah A, Johar D, et al. What role does the stress response have in congestive heart failure? J Cell Physiol. 2017 May 11. doi: 10.1002/jcp.26003.

9. Marenzi G, Muratori M, Cosentino ER, Rinaldi ER, Donghi V, Milazzo V, et al. Continuous ultrafiltration for congestive heart failure: the CUORE trial. J Card Fail. 2014 May;20(5):378.e1-9.

10. Canaud $\mathrm{B}^{1}$, Bowry SK, Tetta $\mathrm{C}$, Gatti $\mathrm{E}$. The case for treating refractory congestive heart failure with ultrafiltration. Blood Purif. 2014;37 Suppl 2:51-60. 
11. Khan M, Jehangir W, Daood MS, Khan A, Mallick NH. Frequency of anemia and renal insufficiency in patients with heart failure. J Ayub Med Coll Abbottabad. 2010;22(3):87-9.

12. Charlot M, Torp-Pedersen C, Valeur N, Seibæk M, Weeke P, Køber L. Anaemia and long term mortality in heart failure patients: a retrospective study. Open Cardiovasc Med J. 2010;4:173-7.

13. Sandhu A, Soman S, Hudson M, Besarab A. Managing anemia in patients with chronic heart failure: what do we know? Vasc Health Risk Manag. 2010 Apr 15;6:237-52.

14. Kilicgidik A, Dundar C, Tigen MK. Anemia in heart failure. Anadolu Kardiyol Derg. 2012;12:65-70.

15. Oster HS, Benderly M, Hoffman M, Cohen E, Shotan A, Mittelman M. Mortality in heart failure with worsening anemia: a national study. Isr Med Assoc J. 2013;15(7):368-72.

16. Pongsuthana S, Tanghongse V. Correlation of anemia and clinical outcomes in heart failure at Rajavithi Hospital. J Med Assoc Thai. 2014;97:41-7.

17. Kuule JK, Seremba E, Freers J. Anaemia among patients with congestive cardiac failure in Uganda - its impact on treatment outcomes. S Afr Med J. 2009;99(12):876-80.

18. Silverberg DS, Wexler D, Blum M, Keren G, Sheps D, Leibovitch E, et al. The use of subcutaneous erythropoietin and intravenous iron for the treatment of the anemia of severe, resistant congestive heart failure improves cardiac and renal function and functional cardiac class, and markedly reduces hospitalizations. J Am Coll Cardiol. 2000 Jun;35(7):1737-44.

19. Dai Y, Konishi H, Takagi A, Miyauchi K, Daida H. Red cell distribution width predicts short- and longterm outcomes of acute congestive heart failure more effectively than hemoglobin. Exp Ther Med. 2014 Aug;8(2):600-606.

20. Rasheed SZ, Samad A. Exercise Stress Test early after acute Myocardial Infarction: predictive value for subsequent development of Congestive Cardiac Failure. Pak J Cardiol. 1999;10(2-3):41-6.

21. Khan Z, Khan B, Hiader I, Khan I, Din J, Khan H, et al. Etiology of congestive heart failure at a tertiary care hospital. Rawal Med J. 2010;35(2):141-4.

22. Nasir U, Shahid H, Shabbir MO. Sleep quality and depression in hospitalized congestive heart failure patients. J Pak Med Assoc. 2015;65(3):264-9.

23. Vim S, Ahmadi H. Factors influencing the length of hospital stay of patients with heart failure. Pak J Cardiol. 2005;16(1):29-34. 